Marquette University

e-Publications@Marquette

College of Education Faculty Research and

Publications

Education, College of

9-1-2008

\title{
Supervisors' Reports of the Effects of Supervisor Self-Disclosure on Supervisees
}

Sarah Knox

Marquette University, sarah.knox@marquette.edu

Alan Burkard

Marquette University, alan.burkard@marquette.edu

Lisa Edwards

Marquette University, lisa.edwards@marquette.edu

Jacquelyn J. Smith

Marquette University

Lewis Z. Schlosser

Seton Hall University

Accepted version. Psychotherapy Research, Vol. 18, No. 5 (September 2008): 543-559. DOI. (C) 2008

Taylor \& Francis. Used with permission. 


\title{
Supervisors' Reports of the Effects of Supervisor Self-Disclosure on Supervisees
}

\author{
Sarah Knox ${ }^{1}$ \\ Department of Counseling and Educational Psychology, School of \\ Education, Marquette University \\ Milwaukee, WI \\ Alan W. Burkard ${ }^{1}$ \\ Department of Counseling and Educational Psychology, School of \\ Education, Marquette University \\ Milwaukee, WI \\ Lisa M. Edwards ${ }^{1}$ \\ Department of Counseling and Educational Psychology, School of \\ Education, Marquette University \\ Milwaukee, WI \\ Jacquelyn J. Smith ${ }^{1}$ \\ Department of Counseling and Educational Psychology, School of \\ Education, Marquette University \\ Milwaukee, WI \\ Lewis Z. Schlosser ${ }^{2}$ \\ Department of Professional Psychology and Family Therapy, \\ College of Education and Human Services, Seton Hall University \\ South Orange, NJ
}




\begin{abstract}
Using consensual qualitative research, researchers interviewed 16 supervisors regarding their use of self-disclosure in supervision. Supervisors reported that their prior training in supervisor self-disclosure (SRSD) came via didactic sources and encouraged judicious use of SRSD. Supervisors used SRSD to enhance supervisee development and normalize their experiences; supervisors did not use SRSD when it derailed supervision or was developmentally inappropriate for supervisees. In describing specific examples of the intervention, SRSD occurred in good supervision relationships, was stimulated by supervisees struggling, was intended to teach or normalize, and focused on supervisors' reactions to their own or their supervisees' clients. SRSD yielded largely positive effects on supervisors, supervisees, the supervision relationship, and supervisors' supervision of others.
\end{abstract}

Research on self-disclosure in therapy has a long history, for such revelations lie at the very heart of therapy (e.g., Jourard, 1971). Supervision of therapists-in-training, on the other hand, has received increased empirical attention only over the past 20 to 30 years (Gray, Ladany, Walker, \& Ancis, 2001; Ladany, Friedlander, \& Nelson, 2005; Ladany \& Walker, 2003; Yourman, 2003). Although the existing research on self-disclosure has fostered a solid understanding of both therapist and client self-disclosure, less is known about supervisor selfdisclosure (SRSD) as an intervention in supervision. We thus sought to examine SRSD, hoping that the findings of this study would increase the profession's understanding of its potential impact and thus facilitate effective supervision practices. To set the foundation for this study, we first briefly examine the literature on both supervision and SRSD.

\title{
Supervision
}

Supervision is "an intervention provided by a more senior member of a profession to a more junior member(s) of that same profession" (Bernard \& Goodyear, 2004, p. 8). Via such interventions, more senior members monitor the quality of professional services provided by junior members and serve as gatekeepers for those entering the profession. The supervision relationship is thus evaluative in nature, takes place over an established period of time, and seeks to enhance the professional functioning of the junior members (Bernard \& Goodyear, 2004). Supervisors may, however, follow different supervision models, including psychotherapy theory-based (e.g., psychodynamic, person centered, cognitive-behavioral), 
developmental (e.g., integrated developmental model; Stoltenberg, McNeill, \& Delworth, 1998), and social role models (e.g., discrimination model; Bernard, 1979). Supervisors likely also vary with respect to their style and the unique manner in which they approach and respond to supervisees (e.g., attractiveness, interpersonal sensitivity, task orientation; Friedlander \& Ward, 1984).

Furthermore, the working alliance is central to supervision (Ladany, Walker, \& Melincoff, 2001; Lehrman-Waterman \& Ladany, 2001) and consists of mutual agreement between supervisor and supervisee about the goals and tasks of supervision as well as the emotional bond between supervisor and supervisee (Bordin, 1983). Specifically, a strong supervision working alliance is related to a balanced supervisory style (i.e., effective combinations of attractiveness, interpersonal sensitivity, and task orientation; Ladany et al., 2001) and is also positively associated with effective evaluation practices in supervision (Lehrman-Waterman \& Ladany, 2001). A weak supervisory alliance, on the other hand, is related to supervisees' withholding information (Hess et al., in press; Ladany, Hill, Corbett, \& Nutt, 1996), to counterproductive events in supervision (Gray et al., 2001), and to conflictual supervisor relationships (Nelson \& Friedlander, 2001).

\section{Supervisor Self-Disclosure}

In his recent chapter, Farber (2006) provided a helpful framework for existing theory and research on SRSD. He discussed the supervision relationship (i.e., dyadic influence between supervisor and supervisee) as well as the personal and professional characteristics of supervisor and supervisee (e.g., personality, work ethic) as influential factors contributing to the use and effectiveness of self-disclosure in supervision. He also acknowledged the difficult balancing act supervisors must maintain: By nature, supervisors should be supportive yet challenging to create an effective training environment, provide appropriate critical feedback without evoking resistance, focus on the supervisee's personal issues and therapeutic skills, and be mindful of the boundary between supervision and psychotherapy. In addition, supervisors must consider the possible effects of disclosing, or not disclosing, on supervisees. Farber (2006) theorized that when 
supervisors chose to disclose, they did so to strengthen the supervision relationship; share what they had learned from their professional experiences; model therapy skills; and provide feedback to supervisees regarding their clinical work, interpersonal style, as well as strengths and areas for growth. Given this context, we now turn to the empirical literature itself.

With regard to the types of SRSD given, supervisees reported that supervisors most often self-disclosed about personal issues (e.g., marital status, religious affiliation; Ladany \& Lehrman-Waterman, 1999). In decreasing frequency, they also disclosed about neutral counseling experiences (e.g., how to deal with a suicidal client), counseling struggles, counseling successes, professional experience, reactions to a supervisee's clients, the dynamics of the training site, the supervisory relationship, didactic mentoring, and experiences as a supervisor.

Norcross and Halgin (1997) reviewed literature examining the effects of SRSD on the supervisee and the supervision relationship. They found that SRSD fostered an environment in which supervisees felt comfortable addressing their concerns and thus cultivated a trusting relationship between supervisor and supervisee, a presumption supported by the work of Bahrick (1990) and Yourman (2003). Yourman (2003) also discussed anecdotal evidence that SRSD may ease supervisee shame and, therefore, increase a supervisee's willingness to self-disclose. Furthermore, research informed by supervisees' reports has demonstrated that when supervisors and supervisees did not self-disclose, communication was impeded, potentially imperiling the supervisory working alliance and supervisees' clinical work and development (Hess et al., in press; Ladany et al., 1996; Ladany \& Melincoff, 1999).

Ladany and Lehrman-Waterman (1999) also noted a relationship between SRSD and the working alliance: The greater the number of self-disclosures perceived by the supervisee, the stronger the supervisee perceived the supervisory working alliance. Ladany et al. (2001) similarly found a positive relationship among supervisory style, supervisory working alliance, and SRSD. The authors hypothesized that self-disclosure may thus be useful to strengthen or 
repair the supervisory relationship and may also help demonstrate a warm, collegial, invested supervisory style. Furthermore, a supervisor may disclose in-the-moment reactions to supervisees to facilitate the supervisee's disclosure of information he or she would otherwise find difficult to share. This process of SRSD leading to supervisee selfdisclosure is also supported by the work of Yourman (2003). Moreover, a good supervisor was identified by supervisees as one who emphasized mutuality of the relationship, made an investment in the supervisee's success, and possessed a willingness to share his or her own experiences and mistakes (Walsh, Gillespie, Greer, \& Eanes, 2002), perhaps via SRSD.

Despite the empirical evidence demonstrating that SRSD can facilitate supervisee self- disclosure and the implicit knowledge that supervision rests on the willingness of supervisees to self-disclose their concerns and clinical experiences with supervisors, research shows that both supervisors and supervisees nevertheless hide information from each other (Hoffman, Hill, Holmes, \& Frietas, 2005; Ladany et al., 1996; Ladany \& Melincoff, 1999). Ladany and Melincoff, for example, found that $98 \%$ of supervisors withheld information from their supervisees, including negative reactions to supervisees, supervisors' own personal concerns, concerns that supervisors anticipated supervisees would react to negatively, positive reactions to supervisees' professional performance, and reactions to supervisees' clients. Research has identified the following reasons for supervisors refraining from such self-disclosures to supervisees: irrelevance of the information to supervision, pertinence of information to the supervisor's personal issues (i.e., supervisors withheld information that might be construed as personal), lack of supervisee developmental readiness to hear the information, and anticipated negative reaction from the supervisee (Hoffman et al., 2005; Ladany \& Melincoff, 1999).

Perhaps as an additional explanation for such nondisclosure, there remains some controversy about SRSD, with concerns raised about its potential deleterious effects. Gray et al. (2001) defined a counterproductive event as "any experience that supervisees identify as hindering, unhelpful, or harmful in relation to their growth as therapists" (p. 371) and found that SRSD was counterproductive when 
the disclosure dismissed supervisees' thoughts and feelings or was unempathic. In response to such counterproductive events, supervisees reported a weakening of the supervisory relationship, a change in their approach to their supervisors, and negative effects on supervisees' work with clients.

Overall, however, supervisees have reported that the majority of their supervisors self-disclose within supervision (Ladany \& Lehrman-Waterman, 1999). Research has also supported a connection between increased self-disclosure and a stronger supervision working alliance (Ladany \& Lehrman-Waterman, 1999) and suggested that refraining from self-disclosure (supervisor or supervisee) may be detrimental to the working alliance and clinical work (Ladany et al., 1996; Ladany \& Melincoff, 1999). The intervention should be used carefully, however, as reflected in Gray et al.'s (2001) assertion of its possible negative impact. As yet unaddressed in the extant research is how SRSD is actually experienced by supervisors themselves, which is the focus of the current study.

\section{Current Study}

Because supervision is an integral part of many psychologists' careers (Bernard \& Goodyear, 2004), it is crucial that research be conducted to inform its effective practice. As indicated previously, although there is some research on SRSD overall, little of it has examined how such disclosures are experienced by supervisors. SRSD thus merits greater empirical attention, given the potential impact of this intervention. Additionally, because most of the available research on SRSD is quantitative or anecdotal in nature, a deeper understanding of SRSD in supervision may be gained through a qualitative approach, which seeks detailed descriptions and an understanding of processes and individual experiences currently missing from the literature on SRSD. Moreover, a qualitative method may enhance our understanding of the potential connection between SRSD and supervisee self-disclosure by allowing a deeper examination of self-disclosure as experienced by supervisors. If such a link exists, supervisors may learn how to better facilitate supervisee disclosure, the very heart of the supervision endeavor, through the appropriate use of SRSD. Finally, researchers have also noted the importance of 
studying the meanings and intentions behind SRSD (Baxter \& Sahlstein, 2000).

The current study thus sought to examine supervisors' perspectives of the antecedents, events, and consequences of one example of their use of SRSD. Although such interventions are not necessarily rare, as noted previously, we wished to increase our understanding of the effects of SRSD by asking supervisors to explore fully one particular instance of SRSD. Given the early stage of research in this particular area (i.e., participants' actual experiences of SRSD), we chose to interview supervisors only: As the deliverers of this intervention, they initiate the SRSD process and thus rightly warrant research attention. The authors hoped, then, that the results might facilitate more effective supervisory interventions through a deeper understanding of how, why, and to what effect self-disclosure is used by supervisors. Based on the definition of therapist self-disclosure developed by Hill and Knox (2002), we define SRSD as occurring when a supervisor reveals information about her-or himself or reveals reactions and responses to the supervisee as they arise in supervision.

\section{Method}

\section{Research Design}

Given our currently limited understanding of SRSD, we selected consensual qualitative research (CQR; Hill et al., 2005; Hill, Thompson, \& Williams, 1997) for this study. This method fosters an exploration of supervisors' experiences of self-disclosure in supervision. Additionally, CQR allows unexpected findings to surface via its inductive process in which participants' experiences are probed without predetermined responses in mind. Finally, CQR enables researchers to rely on the actual language of the participants to guide the data analysis and the emerging findings regarding SRSD. 
NOT THE PUBLISHED VERSION; this is the author's final, peer-reviewed manuscript. The published version may be accessed by following the link in the citation at the bottom of the page.

\section{Participants}

\section{Supervisors}

Sixteen supervisors (nine men, seven women; 15 European American, one Asian) participated in the study. (An additional person was interviewed but was not included in the study because the SRSD incident did not fit the study parameters.) Fourteen were licensed psychologists (11 counseling psychologists, three clinical psychologists), and two had doctoral degrees and were credentialed as counselor educators. One participant had graduated from the doctoral program in which the primary team resided. Supervisors ranged in age from 30 to 67 years $(M=49.00)$ and came from the Midwest and MidAtlantic regions of the United States. Participants reported completing between 0 and 2 courses on supervision $(M=.94)$; between 0 and 4 supervision practica $(M=.88)$; and between 0 and $40+\mathrm{hr}$ of supervision-related postdoctoral, continuing education, class, or training experiences (participants often reported these data as ranges; thus, we cannot calculate a mean or standard deviation). With regard to other supervision-related training received, three participants indicated that their internship included supervision training; two noted involvement in supervision of supervision (either as supervisor or supervisee); and one each mentioned receiving her or his own supervision (e.g., as a therapist), attending presentations on supervision research, supervising less advanced students in her or his graduate program, or writing supervision texts as sources of additional learning about supervision. In terms of the supervision that these participants had provided to others, they had been supervising between 5 and 35 years $(M=16.39)$, between 0 and 6 years of which was prelicensure $(M=2.54)$ and between 1 and 34 years of which was postlicensure $(M=14.19)$. Eleven of the participants were known professionally to one or more researchers (e.g., supervised the program's practicum students, served on program students' dissertation committees) but were not primarily affiliated with the researchers' programs, nor were they the 11 counseling psychologists.

The 16 supervisees (15 women, one man; 10 European American, two African American, one Latina/o, three "other") discussed by our participants ranged in age from the mid-20s to 47 
years. They likewise varied in program status, from first-year graduate students to postdoctoral residents. (Because of recruiting challenges, we allowed participants to discuss an example of SRSD with any prelicensure supervisee; see Appendix B.) Most had minimal clinical experience before the SRSD (from none to "not a lot"), although two had more such experience ("a good degree" or "2 years"). Dividing the total length of the supervision relationship (which ranged from one semester to 2 years) into thirds, six of the supervisors identified the specific SRSD as occurring early in their relationship with the supervisee, four as occurring about halfway through, and two as occurring toward the end of supervision (not all participants provided complete data for this question).

\section{Interviewers and judges}

Three counseling psychologists and one counseling psychology doctoral student (a 45-year-old European American woman, a 48year-old European American man, a 33-year-old biethnic [Latina/European American] woman, a 24-year-old European American woman) conducted the telephone interviews and were the judges on the primary research team. Two interviewers/judges were associate professors and one was an assistant professor at the time of the study. An assistant professor of counseling psychology (a 34-year-old White male American Jew) served as auditor. All were authors of the study, and three had prior experience with CQR. Three of the five authors had worked together on previous studies, and the remaining two were members of the department in which all but the auditor worked. Thus, the team members had strong professional relationships, were respectful of each other, and enjoyed doing research together. To ensure that the team was indeed operating consensually, we periodically talked about how the research process was going and addressed any questions or concerns. Questions raised by those newer to CQR were answered, and no concerns about the nature of the analysis process or the tenor of the team were raised. The authors' biases appear in Appendix A. 
NOT THE PUBLISHED VERSION; this is the author's final, peer-reviewed manuscript. The published version may be accessed by following the link in the citation at the bottom of the page.

\section{Measures}

\section{Demographic form}

The demographic form asked for basic information about the participant/supervisor: age, sex, race/ethnicity, supervision training experiences, years of experience providing supervision (both pre-and postlicensure), and field of study. In addition, the form asked participants to give their name and contact information so that researchers could arrange for the first interview.

\section{Interview protocol}

The protocol was developed collaboratively by all team members (e.g., the primary team collectively developed the questions based on their knowledge and experiences as supervisors/supervisees; they then sought and incorporated feedback from the auditor to refine the protocol). The resulting semistructured interview protocol (i.e., all participants responded to a standard set of questions, with interviewers pursuing additional topics that emerged from participants' responses; see Appendix $B$ ) began with a reminder of the definition of self-disclosure used in this study (i.e., "When verbally self-disclosing, a supervisor reveals information about her-or himself or reveals reactions and responses to the supervisee as they arise in supervision"). The first set of questions asked participants to provide some background information regarding the supervision they provide. The next section of the interview focused on their recollections and perceptions of a specific supervisory self-disclosure event and included a number of questions. The interview closed by asking participants about the effect of the interview and their reasons for participating in the research.

In the follow-up interview, the researcher asked any further questions that may have arisen after the first interview or clarified prior responses; likewise, the participant could also add to or amend any information given in the first interview. Thus, this second interview adhered to no distinct format but instead flexibly accommodated to the content that the interviewer or participant wished to pursue further (e.g., participants offered additional content related to an earlier 
NOT THE PUBLISHED VERSION; this is the author's final, peer-reviewed manuscript. The published version may be accessed by following the link in the citation at the bottom of the page.

response; the researcher asked for clarification of an area from the initial interview). Data from both interviews were considered in the data analysis.

\section{Procedures for Collecting Data}

\section{Recruiting supervisors}

A list was generated of all American Psychological Associationaccredited counseling center internship sites in the hope that such sites' strong culture of supervision would be fertile territory for potential participants. From this initial list of 107 sites, we randomly chose 50 sites from across the United States; within each of these 50 sites, we randomly chose one individual to contact (i.e., the second psychologist listed as long as she or he was not the clinic director), to whom we then mailed a packet of study materials (cover letter, informed consent, demographic form, interview protocol). Included in these packets were the criteria for participation (licensed psychologists/counselors who have provided clinical supervision to supervisees for at least 3 years postlicensure; must have had an experience of supervision-related self-disclosure with a supervisee in individual supervision within the last 2 years; the supervisee to whom they disclosed must have been a preinternship master's-or doctorallevel practicum student or a predoctoral intern who met with the supervisor at least weekly for an hour of individual face-to-face supervision for at least one academic term). The yield of this first round of contact was one participant/supervisor. After sending a follow-up e-mail, we yielded a second participant/supervisor. We then recruited participants/supervisors via snowball sampling, in which practicing psychologists/supervisors known to the researchers were contacted in person or by e-mail about the study and asked to participate. In addition, they were asked to pass along information about the study to their colleagues, who could then also pass the information along to others. The yield from the snowball sampling was 14 participants/supervisors, for a total of 16 supervisors for the study.

Psychotherapy Research, Vol. 18, No. 5 (September 2008): pg. 543-559. DOI. This article is (C) Taylor \& Francis (Routledge) and permission has been granted for this version to appear in e-Publications@Marquette. Taylor \& Francis (Routledge) does not grant permission for this article to be further copied/distributed or hosted elsewhere without the express permission from Taylor \& Francis (Routledge). 
NOT THE PUBLISHED VERSION; this is the author's final, peer-reviewed manuscript. The published version may be accessed by following the link in the citation at the bottom of the page.

\section{Interviewing}

The protocol was piloted on two nonparticipant volunteers who closely fit the criteria for participation. On the basis of feedback received via these pilots, we revised the protocol (e.g., clarification of question wording, deletion of redundant questions). Each of the four primary team members then completed both the initial and follow-up audiotaped telephone interviews with between three and five supervisors. Following each interview, the researcher noted the length of the interview and the level of rapport developed with the participant. At the conclusion of the 50-to 60-min first interview, the follow-up interview was scheduled for approximately 2 weeks later. At the end of the 5-to 20-min follow-up interview, researchers thanked supervisors for their participation.

\section{Transcripts}

All interviews were transcribed verbatim (except for minimal encouragers, silences, and stutters). Any identifying information was removed from the transcripts, and each participant was assigned a code number to protect confidentiality.

\section{Procedures for Analyzing Data}

Data were analyzed according to CQR methods (Hill et al., 1997, 2005). Because this qualitative method is well known, we do not include a detailed explanation of CQR here. Readers interested in a complete description are referred to Appendix C. CQR relies on research team members arriving at consensus about data classification and meaning as they proceed through the three steps of data analysis (domain coding, core ideas, cross-analysis), with review of each step by an external auditor. We also assessed the stability of the crossanalysis categories by withholding two of the original cases from the initial cross-analysis. We found that the domains and categories were stable (i.e., the category titles were not altered by the later insertion of the two withheld cases).

Participant-supervisors who requested $(n=14)$ were sent a draft of the final results of the study for their comments. We asked them to

Psychotherapy Research, Vol. 18, No. 5 (September 2008): pg. 543-559. DOI. This article is (C) Taylor \& Francis (Routledge) and permission has been granted for this version to appear in e-Publications@Marquette. Taylor \& Francis (Routledge) does not grant permission for this article to be further copied/distributed or hosted elsewhere without the express permission from Taylor \& Francis (Routledge). 
examine the degree to which their own experiences had been reflected in the group results depicted in the draft. They were also asked to verify that their and their supervisees' confidentiality was maintained in any illustrations contained in the results. Three participants responded, indicating that their experiences were indeed reflected in the collective results; they expressed no concerns about confidentiality and suggested no substantive changes.

\section{Results}

Given the relatively large number of participants in this CQR study $(N=16)$, we used a four-category system to present the findings (as opposed to CQR's standard three-category system of general, typical, and variant), as suggested by Hill et al. (2005). Thus, general findings applied to all or all but one case (i.e., 15-16 cases), typical findings to more than half and up to the cutoff for general findings (i.e., 9 -14 cases), variant findings to at least four and up to half of the cases (i.e., 4-8 cases), and rare findings to between two and three cases. Findings that emerged in a single case were placed into an "other" category and are not reported here. Because of space limitations, we present only general, typical, and variant findings in the text; rare findings may be found in the tables.

We first present the results that emerged when participants (i.e., supervisors) recalled the training they had received about SRSD, their reasons for disclosing and not disclosing as supervisors, and the types of SRSDs they commonly gave (Table I). These findings provide a context and foundation on which readers may view the subsequent results. Because they were not the central focus of the study, however, we present only a brief overview of these findings and direct readers to Table I for a more detailed presentation. We then present the findings that emerged when supervisors recalled a specific example of SRSD (Table II), the primary focus of this study.

\section{Contextual Results}

Supervisors typically received their training about SRSD in didactic experiences and variantly in their own supervision (as supervisees). The message typically conveyed was that SRSD, when 
used carefully, can be helpful to supervisees. As reasons for using SRSD, supervisors typically used the intervention to teach or enhance supervisee development as well as to normalize. They variantly used SRSD to strengthen the supervision relationship or to model or increase supervisee disclosure in supervision. As reasons for not using SRSD, supervisors generally avoided this intervention when it would derail supervision. More specifically, they variantly noted that they would not disclose if doing so would cross a boundary, was for the benefit only of the supervisor, or would damage the supervisee. They also typically reported that they would not use SRSD if the supervisee was not developmentally ready for a disclosure. The types of SRSD used generally arose from supervisors' clinical experiences. For example, they typically disclosed about their personal or emotional reactions, therapy experiences similar to those of their supervisees, or their own therapy mistakes. They also typically disclosed about the supervision process and relationship as well as their personal biographical information. Finally, they variantly disclosed about their training experiences or professional development.

\section{Results for Specific Event of Supervisor Self-disclosure}

Supervisors typically enjoyed a good relationship with the supervisee to whom they self-disclosed ( "It was a very positive and wonderful relationship"; "We connected well and had good rapport") but variantly reported the relationship as business-like ("The relationship was productive and professional [but] we talked just about clients ...the relationship was more professional than warm") or tenuous (the supervisor "found the supervisee a little difficult and did not feel an inherent connection often felt with other supervisees"). The precipitant or stimulus for the SRSD was typically the supervisor's sense that the supervisee was struggling. More specifically, supervisors variantly reported that supervisees struggled when intervening with clients ("The supervisee was stuck and wondered what to do with the client and also did not understand how to identify the client's 'triggers"') and with their emotional reactions to clients ("The supervisee saw a client with borderline personality disorder who was trying to cross lots of boundaries, which triggered the supervisee's inadequacies and made the supervisee angry with the client"). Via the SRSD, supervisors typically intended to teach or improve supervisees' 
clinical work ("to help the supervisee conceptualize the client"; "to teach that clients may deceive for lots of reasons and that such deceit is not necessarily pathological but can be self-protective'"), as well as to normalize ("to let the supervisee know that the client had done similar things with prior therapists"; "to let the supervisee know that she was not alone in her feeling anxious").

The actual content of the SRSD typically focused on supervisors' reactions either to their own or to their supervisees' clients (the supervisor "shared some misgivings and feelings regarding working with Axis II clients"; the supervisor "shared [his] internal dialogue about the supervisee's client" and what the supervisor was thinking) and variantly focused on supervisors' personal life or professional development (the supervisor "was concerned about the inconsistent nature of supervision because of what was going on" in the supervisor's personal life). The effect of the SRSD was generally positive for supervisors. For example, they typically reported that the SRSD seemed helpful and effective ("It felt good to have helped the supervisee"; the supervisor "was excited because the SRSD helped the supervisee use supervision for personal growth") and variantly reported a sense of relief after giving the SRSD (the supervisor "was relieved that [she] was wrong in thinking that the supervisee did not value" the supervisor). Supervisors also perceived that the SRSD had generally positive effects for supervisees. For instance, the intervention typically appeared to increase supervisee self-disclosure ("The SRSD enabled the supervisee to discuss difficult and negative concerns"; "The supervisee was more open in trying to process emotional issues about being a therapist") and variantly seemed to enhance supervisee learning ("The SRSD gave the supervisee something 'tangible to do' with the client and the supervisee learned a useful way of thinking"), seemed helpful and effective ("The supervisee indicated that it was helpful to hear about how to maintain boundaries"), and appeared to elicit a sense of relief and relaxation in supervisees ("The supervisee seemed relieved to not have to worry about theoretical orientation as much"). Other effects (e.g., negative effects, supervisees being surprised by the SRSD) also variantly emerged ("The supervisee was 'stunned"' and then thanked the supervisor for the SRSD). The SRSD typically appeared to have positive effects on the supervision relationship as well. More 
specifically, it typically seemed to enhance the relationship ("The SRSD drew [us] closer;" "There was increased comfort in the supervision relationship") and variantly appeared to affect how supervisor and supervisee discussed clinical work ("The SRSD opened up a conversation about what the client's goals should be, how the supervisee could address goals with the client, and how the supervisee might work with the client' ${ }^{\prime \prime}$ ).

Supervisors also perceived that the disclosure typically had positive effects on their supervision of others ("The SRSD provided an example of the importance of being real with supervisees, of genuinely sharing one's experience"; "The experience provided validation that SRSD works and that [I] will continue to use it when appropriate") and variantly appeared to have no effect on such supervision (the supervisor "does not think this SRSD affected [his] use of SRSD with other supervisees"). Finally, supervisors typically indicated that they would do nothing different with regard to the SRSD (the supervisor "would not do anything different because it turned out well"; overall the supervisor 'felt the SRSD was 'pretty positive' and a good way to handle the issue"), and variantly reported that they would change their approach in some way (the supervisor "might be less direct").

\section{Pathway}

We examined the general and typical categories of the specific event findings to ascertain whether there might be a common pathway or progression that characterized the results, as recommended by Hill et al. (1997, 2005; Figure 1). In this process, if at least half of the cases from one category level carried through to the next category level, the link in the pathway was noted. For those that did not meet this threshold, no such link appears.

The findings indeed suggest a shared pathway for these supervisors' experience of self-disclosure in supervision. In the context of a good supervision relationship, supervisors notice their supervisees struggling. Intending to teach/improve clinical work and/or normalize, supervisors disclosed their reactions to their own or their supervisees' clients. This disclosure appeared to have largely positive effects on the supervisor, the supervisee, the supervision relationship, and the 
NOT THE PUBLISHED VERSION; this is the author's final, peer-reviewed manuscript. The published version may be accessed by following the link in the citation at the bottom of the page.

supervisors' supervision of others. We do not assert this as a causal pathway but instead present it as the pattern that emerged from these supervisors' experience of self-disclosure.

\section{Prototypical Example}

We provide here a prototypical example of these supervisors' self-disclosure experience, based on the general and typical results. We incorporate details from specific cases to bring the findings to life.

Andy $^{3}$ was a 50-year-old European American male supervisor who had completed one course (including a practicum) in supervision and approximately $25 \mathrm{hr}$ of supervision-related postdegree training and had been practicing as a licensed psychologist for more than 15 years. Andy's supervisee, Susan, was a 31-year-old European American female in her second year of a master's program. Andy's disclosure occurred 1 month into Susan's first year-long practicum, during which Susan was counseling a couple in whom the female partner (Bridget) had been diagnosed with borderline personality disorder (BPD).

Andy described his relationship with Susan in positive terms ("I would say it's pleasant, I would say we have a good working relationship. I value ...the skills she has"). Furthermore, Susan abided by the clinic's rules and expectations, turned in her paperwork on time, and "worked hard to make clinic life easy." Andy noticed that Susan was struggling with her emotional reactions to Bridget, specifically the difficulty of being "glorified" as a therapist in one moment and "devalued" the next: "[Bridget] ... initially started out the session really glorifying the work that [Susan] was doing and saying wonderful things about it, and I would caution [Susan], you know, that can switch pretty easily with a borderline ...so I sort of prepared her over time for coming down off of the pedestal." Although Andy tried to prepare Susan to be "knocked off her pedestal" by Bridget, Susan stated that it felt painful and upsetting when it actually happened. Andy intended his disclosure to teach Susan to "make the best of a situation," in which Bridget tried to shift the focus from herself to her therapist, and also to help Susan refocus the therapy on Bridget. In addition, Andy sought to normalize Susan's experience of 
working with clients with BPD ("[I hoped] to try and give her some consolation in her discomfort and to normalize the experience that when you work with borderline clients, this is what happens, this is not unusual"). Susan's evident discomfort stimulated Andy to disclose that he had also worked with clients with BPD, who may, in a single session, begin by idealizing the therapist but then see them as the worst counselor ever: "Yes, that's happened to me also in the course of a similar session where you can start out the session being idealized by the client and midway through, through no action different than you've been taking, become devalued, severely devalued." Andy acknowledged how emotionally difficult it is to experience such shifts as a therapist and discussed what he tries to do to work through the shock and discomfort (e.g., consider what from the client's past may have contributed to this behavior). Andy reported that the SRSD appeared helpful and effective: Susan learned how to manage client reactions, felt her experience was normalized, and increased her own disclosure in supervision. Andy also indicated that the SRSD strengthened their relationship, for they seemed to "join" in the challenges of working with difficult clients. Andy asserted that this SRSD event reconfirmed how much supervisees value hearing their supervisors' lived experiences with clients, that he would not change his approach to this SRSD, and that he was encouraged to continue his appropriate use of SRSD.

\section{Discussion and Practice Implications}

First, we briefly discuss the contextual findings related to participants' overall training and use of SRSD. We then fully discuss the findings related to the specific examples of SRSD.

\section{Contextual Results}

The extant literature does not address the source of supervisors' training about SRSD. Thus, our findings that participants reported learning more often in didactic than in experiential (i.e., supervisory) contexts that careful use of SRSD could be beneficial are an important addition to the literature. It appears, then, that participants were told (e.g., by faculty) that SRSD could be helpful more often than they actually recalled such effects from their own experiences as 
supervisors or supervisees. It may be that these participants never had an opportunity to discuss (with supervisors or supervisees) the use and effects of SRSD, or perhaps participants' supervisors' use of SRSD was relatively unremarkable and was experienced simply as a routine component of the supervision process. The protocol's use of the word "training" (as opposed to a broader term such as "influences") may also have predisposed participants to speak more of didactic than experiential sources. Given how these participants learned about SRSD, it may be prudent for supervisors to engage in a discussion of SRSD with their supervisees. This discussion could certainly take the form of a teaching conversation about using the intervention but may more powerfully occur during and after an actual incident of SRSD, thereby taking a more experiential form. In this way, supervisors and supervisees could discuss why the intervention was used, how it was received, and how it may have affected both supervisor and supervisee. Such conversations may be particularly fruitful when there are cultural differences between supervisor and supervisee, for there may be culturally different perspectives regarding the appropriateness of SRSD that, once illuminated, may prove useful for supervision.

Participants' reasons for using SRSD parallel those in the literature on intentions for therapist self-disclosure (Edwards \& Murdock, 1994; Simon, 1990). Nothing in the extant empirical literature has yet addressed supervisors' reasons for using SRSD, however; thus, our findings again add to the literature in this area. Two of the findings (i.e., to enhance the supervision relationship, to model supervisee disclosure) provide empirical support for those theorized by Farber (2006) and thereby invite additional research to see whether they also emerge in other investigations. Participants' reasons for refraining from SRSD echo those found by Ladany and Melincoff (1999), suggesting that if supervisors fear that the SRSD is irrelevant to supervision or connects too closely to the supervisor's personal concerns, or if supervisees are not ready to hear or will react negatively to the SRSD, prudence may dictate that such SRSDs not be offered. Finally, the types of SRSDs reported by our participants mirror those found in the literature (Ladany \& Lehrman-Waterman, 1999). 


\section{Results for Specific Event of Supervisor Self-disclosure}

Although the majority of these participants perceived a strong supervision relationship before the specific SRSD, some characterized the relationship as more formal (i.e., business-like) or as on shaky footing. Those who experienced a positive relationship parallel the findings of Hutt, Scott, and King (1983) regarding the importance of a warm, accepting, respectful, trusting, and understanding supervision relationship. Given the work of Ladany at al. (2001) and LehrmanWaterman and Ladany (2001), those in the latter two categories (i.e., business-like or tenuous relationship) may have experienced difficulty establishing the working alliance: The business-like relationships may have lacked a strong emotional bond, whereas the tenuous relationships may have suffered along all three dimensions of the alliance (i.e., goals and tasks of supervision, emotional bond between supervisor and supervisee; Bordin, 1983). Furthermore, both Ladany et al. (1996) and Walsh et al. (2002) found a link between the supervision relationship and supervisee disclosure (stronger supervisory relationships are associated with supervisee disclosure). Intriguingly, of those cases that comprise the "tenuous" relationship category, only two appeared in the later category in which one effect of the SRSD on the supervisee was to increase supervisee selfdisclosure. Although there could be many reasons for the SRSD not eliciting more supervisee self-disclosure in these cases, one explanation may be the nature of the supervision relationship itself. In supervision relationships that seem on rocky footing, then, judicious use of SRSD may be one way to enhance the connection between supervisor and supervisee. Because of the inherent evaluative role of supervision, supervisees may be relieved to learn that they need not be perfect, that even their supervisors have made mistakes, and that recovery from such errors is indeed possible. Relatedly, supervisees may then increase their own disclosure after experiencing their supervisor's vulnerability via her or his own SRSD.

The predominant stimulus for the specific examples of SRSD was the supervisors' sense that supervisees were struggling clinically. Unsurprisingly, via the SRSD supervisors then sought to normalize such struggles and to help supervisees improve their clinical work. This process of the more senior member monitoring and then intervening to 
improve the quality of services provided by the more junior member is the very heart of supervision, in which supervisors appropriately fill, as needed, the role of counselor, teacher, or consultant for supervisees (Bernard \& Goodyear, 2004). Although our participants' intentions mirror those found for therapist self-disclosure (e.g., normalization; Edwards \& Murdock, 1994; Simon, 1990), little in the existing literature yet addresses the precipitants or intentions of SRSD. These findings regarding SRSD, then, although seemingly logical and extending our current understanding, nevertheless warrant further investigation. Thus, when supervisors see their supervisees struggling, thoughtful use of SRSD may indeed be helpful, whether intended to teach, enhance clinical work, or normalize supervisees' concerns.

The content of these supervisors' specific examples of SRSD focused primarily on clinical topics but occasionally included information regarding their own personal or professional background, both of which parallel the extant literature (Ladany \& LehrmanWaterman, 1999). The more central focus, then, remained on the clinical realm, reflecting clear attention to the tasks of supervision and also likely addressing both the needs and intentions supervisors perceived that initially stimulated the SRSD. This focus was sometimes balanced, however, by the revelation of information about the supervisor less directly linked with supervision but perhaps more related to their role as professionals with additional experiences and potential wisdom to share with those just entering the profession. Farber's (2006) assertion regarding the openness and mutuality between supervisor and supervisee could well be at play here, allowing supervisors to more freely share information with those who will soon be colleagues.

The perceived effects of these supervisors' SRSDs were predominantly positive for themselves, their supervisees, the supervision relationship, and even for the supervisors' supervision of others. A few noted that their supervisees appeared initially surprised by the SRSD or experienced a short-lived negative effect, but the prevailing impact was one of marked benefit, echoing the existing literature (Bahrick, 1990; Farber, 2006; Hutt et al., 1983; Ladany \& Lehrman-Waterman, 1999; Ladany et al., 2001; Norcross \& Halgin, 1997; Walsh et al., 2002; Yourman, 2003). We note as well that two 
of the common benefits of SRSD here were an enhanced supervision relationship and greater supervisee self-disclosure. Given that supervision is predicated on supervisee self-disclosure, this strikes us as a vital finding, one that illuminates possible ways to repair or strengthen the supervision relationship and process: When supervisors demonstrate their willingness to take appropriate risks by disclosing vulnerable material, supervisees may feel freer to do the same. The largely positive effects of these SRSDs are also seen in the supervisors' comments about what they would do differently regarding this example of SRSD: The majority stated that they would do nothing differently; those who wished to change their approach indicated that they would use SRSD earlier.

The story of these supervisors' SRSD, then, is this: In the context of a good supervision relationship, supervisors sensed their supervisees struggling; to improve their supervisees' clinical work and normalize their struggles, supervisors self-disclosed about clinical content, an intervention that had a number of chiefly positive effects. Thus, by examining the supervisors' actual experience of these SRSDs, we have a clearer sense of the relational foundation that existed before the disclosure, the precipitant and goals for the intervention, the actual content of the intervention, and its perceived effects.

\section{Limitations}

These results are based on the experiences of 16 supervisors, most of whom were European American licensed psychologists, who agreed to be interviewed over the phone about their use of SRSD. It is possible that non-European Americans or nonpsychologist mental health professionals may have had different SRSD experiences, potentially leading to different findings than those reported here. Some of the participants were also known to members of the research team: Although the actual interview, when possible, was done by a researcher not known to the participant, the existence of a professional relationship with another researcher on the primary team may have affected participants' responses. We recognize as well that the primary findings of this research are based on participants' perceptions of the effects of a single instance of SRSD. As such, they may have had difficulty distinguishing the effects of this one instance 
of SRSD from the effects of other SRSDs (neither researchers nor participants assumed that the SRSD described was the only one given in supervision) or other supervision phenomena. Because the instructions given to participants in selecting a specific SRSD event to describe were deliberately broad (see Appendix B), we do not know whether the event they chose to describe was, for example, typical, the most memorable, or the most positive, thereby creating the potential for selection bias. Thus, supervisors may have chosen to explore their particular example of SRSD for reasons of which we are unaware. Furthermore, in following the guidelines of CQR, we have not reported findings that were expressed by only one participant. In addition, we acknowledge that we have only supervisors' recollections and perspectives here and thus do not know how supervisees actually received their supervisors' self-disclosure: Supervisees' experiences of the SRSD may or may not parallel supervisors' perceptions of the intervention. As is customary for CQR studies, we sent potential participants a copy of the interview protocol so that they could provide fully informed consent and could consider their SRSD experiences if they decided to participate. Although knowledge of the interview questions may have facilitated richer responses, it may also have enabled participants to cast their experiences in more socially desirable terms than would have been the case without having seen the protocol (Hill et al., 1997). Despite the mainly positive effects participants noted for their examples of SRSD, it is possible that they had also experienced other SRSDs as having less salutary effects but chose not to report such events for this study. It is possible as well that there were negative effects of the reported SRSDs of which supervisors were unaware.

\section{Implications for Research}

With regard to research, this study also yields fruitful questions for further examination. Most obviously, we have only supervisors' perspectives here. We thus encourage other researchers to deeply examine supervisees' actual experiences of SRSD. In addition, interviewing supervisors immediately after using SRSD in a supervision session may yield illuminating information and may provide data about SRSDs that had less positive effects than those that predominated here. Different types of SRSD may also elicit different effects for 
supervisees, another area ripe for further study. Most of the SRSDs described here focused on supervisors' reactions to their own or their supervisees' clients and had largely beneficial effects. In contrast, only rarely did these supervisors disclose their concerns about the supervision relationship itself. This less frequent broaching of the relationship echoes the findings of Knox, Hess, Petersen, and Hill (1997) that therapists seldom disclosed their immediate reactions to clients. Were these quite distinct types of SRSD, then, experienced similarly by supervisors and by supervisees? Relatedly, when we examined the cross-analysis to see whether a pathway might emerge for the variant and rare findings, we found some evidence of a partial pathway: Supervisors were concerned about the nature of a supervision relationship they described as tenuous and, in an attempt to strengthen that relationship, disclosed their concerns about the relationship. These are preliminary findings indeed and warrant further investigation. We are also curious about how SRSD might be experienced by supervisors and supervisees who come from diverse backgrounds (e.g., age, culture, gender, race, sexual orientation). Furthermore, might there be developmental differences in the types of SRSD that supervisors use as well as those that yield the most salutary effects? For instance, would certain types of SRSD be more or less helpful for supervisees early in their training, and would perhaps different types yield different effects for supervisees more advanced in their training? There is clearly more to be learned about SRSD.

\section{Acknowledgements}

The order of the second through fourth authors is alphabetical; all contributed equally to this project. We thank Rebecca Auld, Jessica Austin, Bethany Bruhn, Jennifer Carrasco, Lauren Dowell, Pamela Ertman, Diane O'Donnell, Katie Pfeffer, Ryan Stengl, and Leah Voigt for transcribing the interviews. We also thank Shirley A. Hess and Cal D. Stoltenberg for reading an earlier draft of this article.

\section{References}

Bahrick, A. S. (1990). Role induction for counselor trainees: Effects on the supervisory working alliance. Dissertation Abstracts International, 51, 1484b. UMI No., 90-14, 392.

Baxter, L. A., \& Sahlstein, E. M. (2000). Some possible directions for future research. In S. Petronio (Ed.), Balancing the secrets of private disclosures (pp. 289-300). Mahwah, NJ: Erlbaum. 
NOT THE PUBLISHED VERSION; this is the author's final, peer-reviewed manuscript. The published version may be

accessed by following the link in the citation at the bottom of the page.

Bernard, J. M. (1979). Supervisor training: A discrimination model. Counselor Education and Supervision, 19, 60-68.

Bernard, J. M., \& Goodyear, R. K. (2004). Fundamentals of clinical supervision (3rd ed.). Boston: Pearson Education.

Bordin, E. S. (1983). A working alliance based model of supervision. The Counseling Psychologist, 11, 35-41.

Edwards, C. E., \& Murdock, N. L. (1994). Characteristics of therapist selfdisclosure in the counseling process. Journal of Counseling and Development, 72, 384-389.

Farber, B. (2006). Supervisee and supervisor disclosure. In B. Farber (Ed.), Self-disclosure in psychotherapy (pp. 180-197). New York: Guilford Press.

Friedlander, M. L., \& Ward, L. G. (1984). Development and validation of the Supervisory Styles Inventory. Journal of Counseling Psychology, 31, 541-557.

Gray, L. A., Ladany, N., Walker, J. A., \& Ancis, J. R. (2001). Psychotherapy supervisees' experience of counterproductive events in supervision. Journal of Counseling Psychology, 48, 371-383.

Hess, S. A., Knox, S., Schultz, J. M., Sloan, L., Brandt, S., Kelley, F., et al. (in press). Predoctoral interns' nondisclosure in supervision. Psychotherapy Research.

Hill, C. E., \& Knox, S. (2002). Self-disclosure. In J. C. Norcross (Ed.), Psychotherapy relationships that work: Therapist contributions and responsiveness to patients. New York: Oxford University Press.

Hill, C. E., Knox, S., Thompson, B. J., Nutt Williams, E., Hess, S. A., \& Ladany, N. (2005). Consensual qualitative research: An update. Journal of Counseling Psychology, 52, 196-205.

Hill, C. E., Thompson, B. J., \& Williams, B. N. (1997). A guide to conducting consensual qualitative research. The Counseling Psychologist, 25, 517572.

Hoffman, M. A., Hill, C. E., Holmes, S. E., \& Frietas, G. F. (2005). Supervisor perspective on the process and outcome of giving easy, difficult, or no feedback to supervisees. Journal of Counseling Psychology, 52, 3-13.

Hutt, C. H., Scott, J., \& King, M. (1983). A phenomenological study of supervisees' positive and negative experiences in supervision. Psychotherapy: Theory, Research and Practice, 20, 118-123.

Jourard, S. M. (1971). Self-disclosure: An experimental analysis of the transparent self. Oxford, England: Wiley.

Knox, S., Hess, S. A., Petersen, D. A., \& Hill, C. E. (1997). A qualitative analysis of client perceptions of the effects of helpful therapist selfdisclosure in long-term therapy. Journal of Counseling Psychology, 44, 274-283.

Psychotherapy Research, Vol. 18, No. 5 (September 2008): pg. 543-559. DOI. This article is (C) Taylor \& Francis (Routledge) and permission has been granted for this version to appear in e-Publications@Marquette. Taylor \& Francis (Routledge) does not grant permission for this article to be further copied/distributed or hosted elsewhere without the express permission from Taylor \& Francis (Routledge). 
NOT THE PUBLISHED VERSION; this is the author's final, peer-reviewed manuscript. The published version may be accessed by following the link in the citation at the bottom of the page.

Ladany, N., Friedlander, M. L., \& Nelson, M. L. (2005). Critical events in psychotherapy supervision: An interpersonal approach. Washington, DC: American Psychological Association.

Ladany, N., Hill, C. E., Corbett, M. M., \& Nutt, E. A. (1996). Nature, extent, and importance of what psychotherapy supervisees do not disclose to their supervisors. Journal of Counseling Psychology, 43, 10-24.

Ladany, N., \& Lehrman-Waterman, D. E. (1999). The content and frequency of supervisor self-disclosures and their relationship to supervisor style and the supervisory working alliance. Counselor Education and Supervision, 38, 143-160.

Ladany, N., \& Melincoff, D. S. (1999). The nature of counselor supervision nondisclosure. Counselor Education and Supervision, 38, 161-176.

Ladany, N., \& Walker, J. A. (2003). Supervisor self-disclosure: Balancing the uncontrollable narcissist with the indomitable altruist. Journal of Clinical Psychology, 59, 611-621.

Ladany, N., Walker, J. A., \& Melincoff, D. S. (2001). Supervisory style: Its relation to the supervisory working alliance and supervisor selfdisclosure. Counselor Education and Supervision, 40, 263-275.

Lehrman-Waterman, D., \& Ladany, N. (2001). Development and validation of the Evaluation Process Within Supervision Inventory. Journal of Counseling Psychology, 48, 168-177.

Nelson, M. L., \& Friedlander, M. L. (2001). A close look at conflictual supervisory relationships: The trainee's perspective. Journal of Counseling Psychology, 48, 384-395.

Norcross, J. C., \& Halgin, R. P. (1997). Integrative approaches to psychotherapy supervision. In C. E. Watkins (Ed.), Handbook of psychotherapy supervision (pp. 203-222). New York: Wiley.

Simon, J. C. (1990). Criteria for therapist self-disclosure. In G. Stricker \& M. Fisher (Eds), Self-disclosure in the therapeutic relationship (pp. 207225). New York: Plenum Press.

Stoltenberg, C. D., McNeill, B. W., \& Delworth, U. (1998). IDM: An integrated developmental model for supervising counselors and therapists. San Francisco: Jossey-Bass.

Walsh, B. B., Gillespie, C. K., Greer, J. M., \& Eanes, B. E. (2002). Influence of dyadic mutuality on counselor trainee willingness to self-disclose clinical mistakes to supervisors. Clinical Supervisor, 21, 83-98.

Yourman, D. B. (2003). Trainee disclosure in psychotherapy supervision: The impact of shame. Journal of Clinical Psychology, 59, 601-609.

Psychotherapy Research, Vol. 18, No. 5 (September 2008): pg. 543-559. DOI. This article is (C) Taylor \& Francis (Routledge) and permission has been granted for this version to appear in e-Publications@Marquette. Taylor \& Francis (Routledge) does not grant permission for this article to be further copied/distributed or hosted elsewhere without the express permission from Taylor \& Francis (Routledge). 
NOT THE PUBLISHED VERSION; this is the author's final, peer-reviewed manuscript. The published version may be accessed by following the link in the citation at the bottom of the page.

\section{Notes}

- $\quad{ }^{1}$ Department of Counseling and Educational Psychology, School of Education, Marquette University \&

- 2Department of Professional Psychology and Family Therapy, College of Education and Human Services, Seton Hall University

- ${ }^{3}$ Pseudonyms are used throughout this prototypical example to protect confidentiality.

- Correspondence: Sarah Knox, Department of Counseling and Educational Psychology, School of Education, Marquette University, $168 \mathrm{H}$ Schroeder Health Complex, Milwaukee, WI 53201. E-mail: sarah.knox@marquette.edu

\section{Appendix A.}

\section{Author Biases}

Before collecting data, the authors discussed their potential biases related to the study's focus. The authors' graduate school training rarely included specific attention to SRSD; when such content was addressed, the theme communicated was to use SRSD sparingly and thoughtfully. When the authors used SRSD, they found it helpful and reported a number of reasons for self-disclosing (e.g., to normalize, to share their thoughts about and approaches to clinical situations, to model decision making, to humanize themselves to supervisees, to build the supervision relationship, to share their insession reactions to supervisees). They indicated that they would not self-disclose if they sensed a boundary problem, if the supervisee seemed to avoid wrestling with the necessary struggles of clinical growth, or if the supervisee was trying to shift the focus of supervision away from her-or himself. When recalling a specific example of SRSD, all noted that it had positive effects, including the supervisee feeling relieved or normalized, increasing her or his disclosure in supervision, or the supervision relationship improving. The effects of SRSDs on supervisors were also usually positive, with supervisors stating that it felt good when supervisees could learn from supervisors' experiences. Two authors, however, noted that they sometimes wondered whether they should have given the disclosure. Overall, their experiences with 
SRSD tended to confirm for the authors the usefulness of SRSD and also stimulated them to think about when and how they used SRSD. The researchers managed these biases both by checking themselves internally (e.g., were they interpreting the data only in light of their own experiences and preferences?) and by checking each other during research meetings (e.g., members of the research team challenged each other if they felt that another's biases were inappropriately clouding an understanding of the data).

\section{Appendix B.}

\section{Interview Protocol}

\section{Self-Disclosure}

When verbally self-disclosing, a supervisor reveals information about her-or himself or reveals reactions and responses to the supervisee as they arise in supervision.

\section{Opening Questions}

1. Please describe your supervisory style (i.e., how you generally work with supervisees, your theoretical approach to supervision).

2. Please describe what, if any, formal or informal training you received about self-disclosure in general and what that training suggested regarding the use of self-disclosure.

a. Training received regarding therapist self-disclosure.

i. What did this training suggest regarding the use of self-disclosure?

b. Training received regarding supervisor self-disclosure.

i. What did this training suggest regarding the use of self-disclosure?

3. Please describe how you generally use self-disclosure in supervision.

a. Please describe your thoughts about the appropriateness of supervisors using self-disclosure in supervision.

b. When you intentionally self-disclose as a supervisor, why do you do so? 
NOT THE PUBLISHED VERSION; this is the author's final, peer-reviewed manuscript. The published version may be accessed by following the link in the citation at the bottom of the page.

c. When you intentionally do not self-disclose as a supervisor, why do you not do so?

d. Please describe some representative examples or types of self-disclosures that you use with supervisees.

\section{Self-Disclosure Event Questions}

Now we'd like you to talk about a specific supervisory self-disclosure event. The event itself may consist of a single self-disclosure statement or more than one self-disclosure statement that occurred within an individual (i.e., not group supervision) supervisor-supervisee interaction within the last 2 years. The supervisee to whom you selfdisclosed was a preinternship master's- or doctoral-level practicum student, who met with you at least once a week for an hour in individual, face-to-face supervision for at least one academic term (e.g., semester, quarter). In this event, you, as supervisor, selfdisclosed and the disclosure(s) had either a clear positive or negative impact.

4. Please describe your relationship with this supervisee before the self-disclosure event.

5. The self-disclosure event:

a. What was happening or what did you observe in supervision that prompted you to self-disclose?

b. What was the content of your disclosure(s)?

c. Why did you deliver the disclosure(s)?

i. What were your intentions for delivering the disclosure(s)?

ii. Please describe the decision-making process you went through as you considered delivering the disclosure(s). iii. How did you anticipate that the disclosure(s) would be received by your supervisee?

d. How did your self-disclosure(s) appear to affect your supervisee?

e. How did the self-disclosure interaction affect you?

f. How, if at all, did the supervision relationship change as a result of the self-disclosure(s)?

g. As you look back, is there anything you would do differently now with regard to the self-disclosure event? 
h. How, if at all, has the self-disclosure event affected your clinical supervision of other students?

i. Would you categorize this event as having positive or negative impact?

6. Please provide some basic demographics of your supervisee (e.g., age, sex, race/ethnicity, year in program, type of program [i.e., master's or doctoral], clinical experience, length of supervision relationship at time of disclosure, total length of supervision relationship).

\section{Closing Questions}

7. Is there anything else you wish to say regarding supervisor selfdisclosure to supervisees?

8. Why did you participate in this research?

9. How did this interview affect you (e.g., reactions, thoughts, feelings)?

\section{Appendix C.}

\section{CQR Method}

\section{Procedures for Analyzing Data}

CQR team members (i.e., first four authors of this article) reached consensus regarding all data analysis decisions; these decisions were then independently reviewed by the auditor (i.e., the fifth author) in the core idea and cross-analysis stages. In reaching consensus, team members discussed their differences in understanding the data until each team member agreed with the final decision regarding the placement of data into domains as well as the development of core ideas and cross-analysis categories. The auditor's feedback was also discussed until the team reached consensus regarding his suggested changes. 
NOT THE PUBLISHED VERSION; this is the author's final, peer-reviewed manuscript. The published version may be accessed by following the link in the citation at the bottom of the page.

\section{Domain coding}

Using the interview questions as an initial foundation, the research team developed a "start list" (Miles \& Huberman, 1994) of domains, or topic areas, used to group data about similar content. Each team member then independently assigned interview data to domain(s). The team next met to discuss their assignment of data to domains until they arrived at consensus for all data. Consistent with $\mathrm{CQR}$ procedures, domains were altered during the analysis to reflect the data more accurately.

\section{Core ideas}

In the next step, for each participant whom a team member interviewed, the team member independently read all of the data in a domain and identified the corresponding core ideas. This process of creating core ideas is referred to as "boiling down" or "abstracting" (Strauss \& Corbin, 1990), with the aim of reducing the data to their essence via core ideas that capture the interview data. After members' independent creation of core ideas for each case, the team discussed the core ideas until they reached consensus on the core ideas' content and wording. This process yielded a consensus version containing the transcribed interview data, here organized into domains, and the corresponding core ideas.

The consensus version was then sent to the auditor, who checked both the assignment of data into domains and the accuracy of the core ideas. The team discussed his feedback until reaching consensus regarding suggested changes to domain coding or core ideas.

\section{Cross-analysis}

This stage of data analysis generates themes or patterns across cases but within a single domain. In this study, responsibility for the domains was divided equally among the primary team members, with each such member developing the categories for the cases within her or his assigned domains. The other primary team members independently examined the proposed category titles with their 
corresponding core ideas and then met to discuss them until reaching consensus on both the category labels and their corresponding core ideas. Core ideas that did not fit into a category were placed into an "other" category for that domain.

The cross-analysis was then sent to the auditor, who examined each category, its core ideas, and the fit among core ideas, categories, and domains. The team reviewed the auditor's feedback and reached consensus regarding the suggested changes. The auditor next reviewed a revised cross-analysis; this process continued until the auditor and research team reached consensus on a final crossanalysis.

\section{Stability check}

Before data analysis, the team randomly selected two cases, which were then withheld from the preliminary cross-analysis of the data. Once this initial cross-analysis had been completed, the data from the stability cases were integrated into the cross-analysis. Team members reviewed these data to determine whether they markedly altered the domains or categories or the frequency designations of general, typical, variant, or rare. The auditor examined the integration of the two new cases into the cross-analysis and provided feedback. The team then reached consensus regarding the auditor's feedback. The findings from this study were deemed stable (i.e., domains, categories, and frequency labels did not markedly change when the stability cases were added to the cross-analysis). 
NOT THE PUBLISHED VERSION; this is the author's final, peer-reviewed manuscript. The published version may be accessed by following the link in the citation at the bottom of the page.

\section{Appendix D}

\section{Table 1. Contextual Information}

\begin{tabular}{|c|c|c|c|}
\hline Domain & Category & Frequency & illustrative core ideas \\
\hline \multicolumn{4}{|c|}{ 1. Training aboul Supervisor Self-disclosure (SRSD) } \\
\hline \multirow[t]{3}{*}{$\begin{array}{l}\text { Source of } \\
\text { training }\end{array}$} & Didactics (pre-ipostdoctorate) & Typical & $\begin{array}{l}\text { Workshope in which we watched role-plays and discuesed } \\
\text { SRSD' }\end{array}$ \\
\hline & Orm supervision (as SE) & Variant & $\begin{array}{l}\text { As trainee, SRs would model use of SRSD, and this where } \\
\text { learned to use SRSO" }\end{array}$ \\
\hline & No SRSD training & Rare & $\begin{array}{l}\text { "No fraining, and do not recall any articles or discussion of } \\
\text { SRSD" }\end{array}$ \\
\hline \multirow[t]{2}{*}{$\begin{array}{l}\text { Meszage } \\
\text { of training }\end{array}$} & $\begin{array}{l}\text { When used carefullyiapproprialely. } \\
\text { can be heipful to SE }\end{array}$ & Typical & "SRSD should only be used for SE's benterl' \\
\hline & Use rarely and with extreme caution & Rare & "SD weh extreme caution" \\
\hline \multirow{4}{*}{$\begin{array}{l}\text { 2. Reasons for } \\
\text { using SRSD }\end{array}$} & To teachuenhance SE development & Typical & To mentor, to teach" \\
\hline & To normalize (SE concerns) & Typical & "Help8 nomalize SE experiences" \\
\hline & To enhance supervision relationship & Variant & "Helps SE relate to SR" \\
\hline & To modelienhance SE disclosure & Variant & "SRSD can stimulate more SESD' \\
\hline \multirow{6}{*}{$\begin{array}{l}\text { 3. Reasons for } \\
\text { not using } \\
\text { SRSD }\end{array}$} & If derails supervision & General & \\
\hline & If crosses boundary & Variant & "If leling about personal things would worry SE" \\
\hline & If done for sakedbenefil of SR & Variant & "Il done to show off or to move things along out of impatience" \\
\hline & If damaging to SE & Variant & "If SD would be damaging for SE to hear at that time" \\
\hline & If SE not developmentally ready & Typical & "II SR wants SE to explore on berfhis own" \\
\hline & If supervision relationship poor & Rate & "If SR doesn't foel sale, doesn't trust SE" \\
\hline \multirow{7}{*}{$\begin{array}{l}\text { 4. Types of } \\
\text { SRSD used }\end{array}$} & SR cinical experiences & General & \\
\hline & Personal/emotional reactions & Typical & "Reactions to SE s casedelient" \\
\hline & $\begin{array}{l}\text { Therapy examples/similat therapy } \\
\text { experiences }\end{array}$ & Typical & $\begin{array}{l}\text { When SE talks about client similar to thoese seen by SR, SR } \\
\text { will share experience (intervention, outcomes) }\end{array}$ \\
\hline & Therapy struggles/mistakes & Typical & "Shares 'messing Lg' in therapy" \\
\hline & Supervision relationship process & Typical & "Moments when SR feels hesitant to provide feecoack to SE" \\
\hline & SR personal biographical information & Typical & "Personal experiences belancing vork and family \\
\hline & $\begin{array}{l}\text { SR training experienceiprolessional } \\
\text { dewelopment }\end{array}$ & Variant & $\begin{array}{l}\text { "Shared experiences as SE and as development theraplst in } \\
\text { treining" }\end{array}$ \\
\hline
\end{tabular}

Note. General=15-16 cases; typical=9-14 cases; variant=4-8 cases; rare=2-3 cases. $\mathrm{SRSD}=$ supervisor self-disclosure; $\mathrm{SR}=$ supervisor; $\mathrm{SE}=$ supervisee; $\mathrm{SESD}=$ supervisee self-disclosure

Table 2. Specific Event of Supervisor Self-Disclosure

\begin{tabular}{|c|c|c|c|}
\hline Domain & Category & Frequency & Illustrative core idea \\
\hline \multirow{3}{*}{$\begin{array}{l}\text { 1. Relationship wSE } \\
\text { pre-SRSD }\end{array}$} & Good & Typical & "Strong, good, collaborative relationship" \\
\hline & Business-like & Variant & $\begin{array}{l}\text { 'A 'fine working relationship' but boundarivived and } \\
\text { business-like" }\end{array}$ \\
\hline & Tenuous & Variant & $\begin{array}{l}\text { "Not a relationship SR enjoyed, was almost a } \\
\text { nonfelationship; SR felt ignofed by SE" }\end{array}$ \\
\hline \multirow{5}{*}{$\begin{array}{l}\text { 2. Precipitant/stimulus } \\
\text { for SRSD. }\end{array}$} & SE struggling & Typical & \\
\hline & $\begin{array}{l}\text { With intervening with } \\
\text { clients }\end{array}$ & Variant & $\begin{array}{l}\text { "SR recognized SE's uncertainty of how to proceed with } \\
\text { client who was going to die' }\end{array}$ \\
\hline & $\begin{array}{l}\text { With emotional reactions } \\
\text { to clients }\end{array}$ & Variant & $\begin{array}{l}\text { "SE was upset with client who was not truthful to SE, } \\
\text { although SE thought she had great relationship with client" }\end{array}$ \\
\hline & With sense of competence & Rare & $\begin{array}{l}\text { "SE scared to show hot-so-good' tape in supervision } \\
\text { because the SE didn't want people to think that the SE } \\
\text { didn't have any counseling skills" }\end{array}$ \\
\hline & $\begin{array}{l}\text { SR concerned about } \\
\text { supervision relationship }\end{array}$ & Rare & $\begin{array}{l}\text { "SR felt frustrated and regretful that supervision has been } \\
\text { so disrupted (because of bad weather and SR's ill child) }\end{array}$ \\
\hline \multirow[t]{4}{*}{ 3. Intentions for SRSD } & $\begin{array}{l}\text { To teach/improve elinical } \\
\text { work }\end{array}$ & Typical & "To heip SE work with client who had a recent loss" \\
\hline & To normalize & Typical & $\begin{array}{l}\text { "To console SE discomfort and to normalize experience } \\
\text { that often happens with clients with borderline personality } \\
\text { disorder" }\end{array}$ \\
\hline & $\begin{array}{l}\text { To improve use of } \\
\text { supervision of supervision } \\
\text { relationship }\end{array}$ & Rare & $\begin{array}{l}\text { "SR didn't want SE, to affect others as SE did SR, because } \\
\text { that vould be detrimental to SE' }\end{array}$ \\
\hline & To increase SESO & Rare & "To help SE disclose, to help SE open up" \\
\hline \multirow[t]{3}{*}{ 4. Content af SRSD } & $\begin{array}{l}\text { SR reactions to own or SE's } \\
\text { clients }\end{array}$ & Typical & $\begin{array}{l}\text { "Shared that thinks SE client is avoiding things and SR } \\
\text { annoyed by that because it seemed that the client was } \\
\text { wasting SE time" }\end{array}$ \\
\hline & $\begin{array}{l}\text { SR personal lifeiprofessional } \\
\text { development }\end{array}$ & Variant & "Disclosed about impending death of relative" \\
\hline & $\begin{array}{l}\text { Concern about supervision } \\
\text { relationship }\end{array}$ & Rare & $\begin{array}{l}\text { "Shared that SR experienced SE as detached and } \\
\text { withholding. hard to connect to" }\end{array}$ \\
\hline
\end{tabular}

Psychotherapy Research, Vol. 18, No. 5 (September 2008): pg. 543-559. DOI. This article is @ Taylor \& Francis (Routledge) and permission has been granted for this version to appear in e-Publications@Marquette. Taylor \& Francis (Routledge) does not grant permission for this article to be further copied/distributed or hosted elsewhere without the express permission from Taylor \& Francis (Routledge). 
NOT THE PUBLISHED VERSION; this is the author's final, peer-reviewed manuscript. The published version may be accessed by following the link in the citation at the bottom of the page.

\begin{tabular}{|c|c|c|c|c|}
\hline \multirow{4}{*}{\multicolumn{2}{|c|}{ On supervisor }} & Postivive & General & \\
\hline & & Seomed helpfuleffective & Typical & $\begin{array}{l}\text { "Folt more "connecting' for SR and SRSD, feit more } \\
\text { colegial than didactic" }\end{array}$ \\
\hline & & Relief & Variant & "Was relieved as SRSD started to 'lighten' SE" \\
\hline & & Negative & Rare & $\begin{array}{l}\text { "Was a bit embarrassing becauso was first time SR shared } \\
\text { 'mistake' that had bad consequences for SR and client' }\end{array}$ \\
\hline \multirow{6}{*}{\multicolumn{2}{|c|}{ On supervisee }} & Positive & General & \\
\hline & & Increased SESD & Typical & 'SRSD brought out more things from SE" \\
\hline & & Enhanced SE learning & Variant & $\begin{array}{l}\text { "Challenged SE to think about her work differently, to trust } \\
\text { gut over following a theoretical orientation" }\end{array}$ \\
\hline & & Seemed helpfuleffective & Variant & $\begin{array}{l}\text { "SE found iz helpful to hear about how to maintain } \\
\text { boundaries" }\end{array}$ \\
\hline & & $\begin{array}{l}\text { SE more relieved and } \\
\text { more relaxed }\end{array}$ & Variant & $\begin{array}{l}\text { "SE appeared refived and became more animated, less } \\
\text { tense" }\end{array}$ \\
\hline & & $\begin{array}{l}\text { Other (e.g., negative or SE } \\
\text { surprised) }\end{array}$ & Variant & $\begin{array}{l}\text { "SE initally became tearful, upeet, not in a negative way but } \\
\text { a therapeutic upset" }\end{array}$ \\
\hline \multirow{4}{*}{\multicolumn{2}{|c|}{$\begin{array}{l}\text { On supervision } \\
\text { relationship }\end{array}$}} & Postive & Typical & \\
\hline & & Enhanced relationship & Typical & $\begin{array}{l}\text { "Alliance strengthened; SR and SE felt joined in the work } \\
\text { together" }\end{array}$ \\
\hline & & $\begin{array}{l}\text { Affected how SR and SE } \\
\text { discussed clinical work }\end{array}$ & Variant & $\begin{array}{l}\text { 'Further teaching has occurred by revisiting concept of } \\
\text { clisnts acting outtre-creating in therapy pain from Iffe' }\end{array}$ \\
\hline & & No change & Rare & "No change" \\
\hline \multirow{2}{*}{\multicolumn{2}{|c|}{$\begin{array}{l}\text { On supervision } \\
\text { of others }\end{array}$}} & Postive & Typical & $\begin{array}{l}\text { "Positive effoct because SR realizes that SES appreciate } \\
\text { reah-world examples from experionosd clinician' }\end{array}$ \\
\hline & & No effect & Variant & "No effect because 'it's what i do' and would do it again" \\
\hline & \multirow{2}{*}{$\begin{array}{l}\text { What SR would do } \\
\text { differently with } \\
\text { SRSD }\end{array}$} & Nothing & Typical & "Nothing because SRSD worked" \\
\hline & & Change approach & Variant & "Would do this SRSD much earliar" \\
\hline
\end{tabular}

Note. General=15-16 cases; typical=9-14 cases; variant=4-8 cases; rare=2-3 cases. $\mathrm{SR}=$ supervisor; $\mathrm{SE}=$ supervisee; $\mathrm{SRSD}=$ supervisor self-disclosure; $\mathrm{SESD}=$ supervisee self-disclosure.

Psychotherapy Research, Vol. 18, No. 5 (September 2008): pg. 543-559. DOI. This article is @ Taylor \& Francis (Routledge) and permission has been granted for this version to appear in e-Publications@Marquette. Taylor \& Francis (Routledge) does not grant permission for this article to be further copied/distributed or hosted elsewhere without the express permission from Taylor \& Francis (Routledge). 
NOT THE PUBLISHED VERSION; this is the author's final, peer-reviewed manuscript. The published version may be accessed by following the link in the citation at the bottom of the page.

\section{Figure 1}

\section{Pathway for general and typical categories of specific event results}

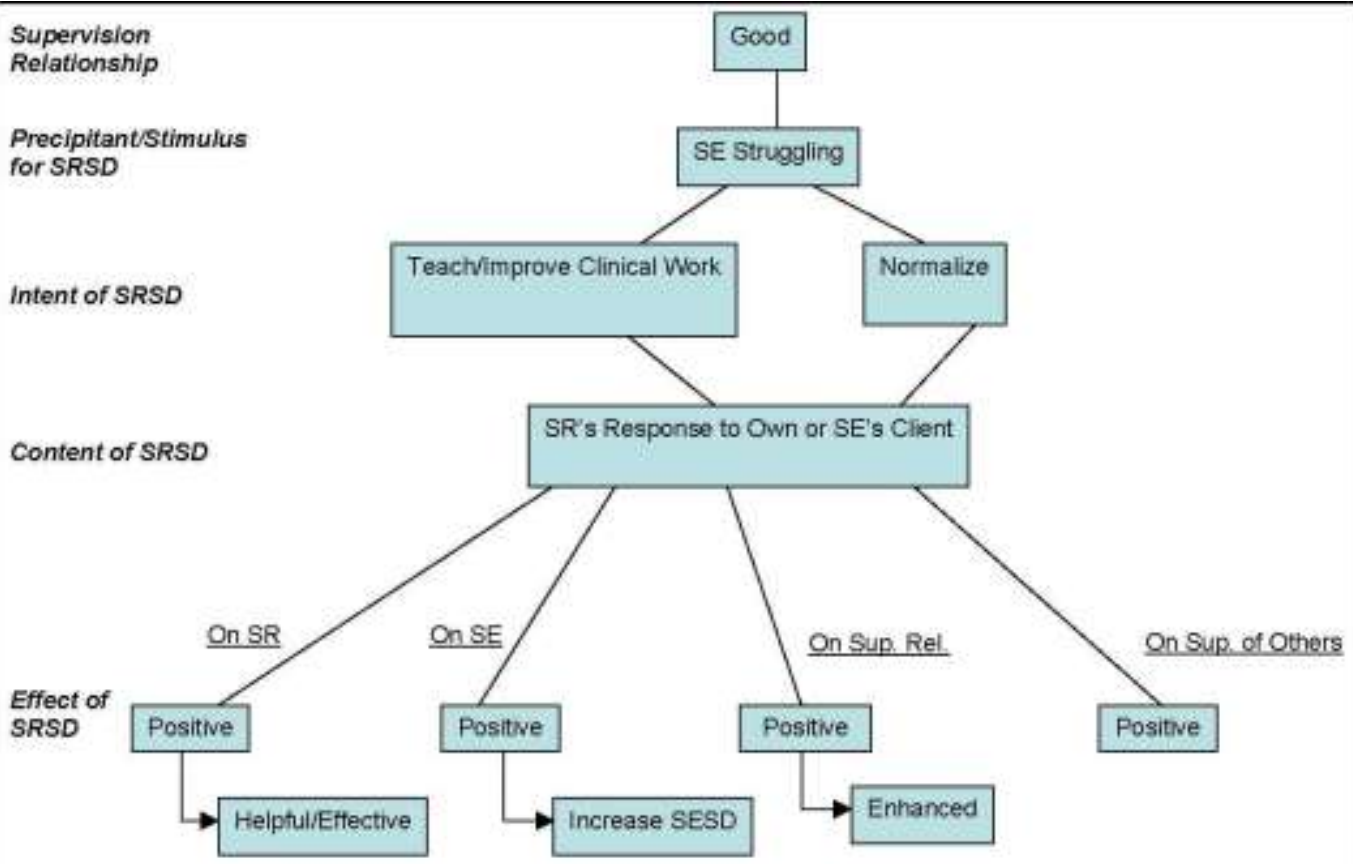

Fieure 1. Pathway for wenctal and twical categories of soecific event results.

Psychotherapy Research, Vol. 18, No. 5 (September 2008): pg. 543-559. DOI. This article is (C) Taylor \& Francis (Routledge) and permission has been granted for this version to appear in e-Publications@Marquette. Taylor \& Francis (Routledge) does not grant permission for this article to be further copied/distributed or hosted elsewhere without the express permission from Taylor \& Francis (Routledge). 